\title{
Evaluating the Effect of Educational Interventions on Health Literacy through Social Networking Services to Promote Students' Quality of Life
}

\author{
Mahnaz Khaleghi', Farkhonde Amin Shokravi ${ }^{1, *}$, Nooshin Peyman ${ }^{2,3}$, Maryam Moridi ${ }^{1}$ \\ 'Department of Health Education and Health Promotion, Faculty of Medical Sciences, Tarbiat Modares University, Tehran, Iran \\ ${ }^{2}$ Social Determinants of Health Research Center, Mashhad University of Medical Sciences, Mashhad, Iran \\ ${ }^{3}$ Department of Health Education and Health Promotion, School of Health, Mashhad University of Medical Science, Mashhad, Iran
}

\begin{abstract}
Background: Studies have shown the health literacy effects on the general state of health and its related factors, as well as health outcomes, physical and mental health, and health-related quality of life. This study aimed to investigate the effect of training based on health literacy through social networking strategies to promote health-related quality of life among students of Islamic Azad University, Shahr Rey Branch, Iran.

Methods: This randomized controlled trial was conducted on 120 students with poor or average quality of life score. Participants were randomly assigned into experimental and control groups (60 participants each). Health literacy and quality of life data were collected at baseline, immediately after, and 3 months after intervention. The educational intervention was conducted online using social networking services. Data were analyzed using SPSS ver. 16.0 (SPSS Inc., Chicago, IL, USA).

Results: The results showed no significant differences between the two groups in terms of health literacy and quality of life at baseline ( $\mathrm{P}=0.979$ and 0.269 , respectively). The mean score of health literacy and quality of life in the experimental group, compared with the control group, significantly increased immediately after and 3 months after the intervention $(\mathrm{P}<0.001)$.

Conclusion: The educational intervention administered by applying health literacy strategies online, through social networking services, can be effective in improving the quality of life of students.
\end{abstract}

Keywords: Health Literacy; Quality of Life; Social Networking; Students

Received: April 30, 2018, Revised: July 12, 2018, Accepted: July 12, 2018

${ }^{*}$ Corresponding Author: Farkhonde Amin Shokravi https://orcid.org/0000-0001-7013-0167

Tel: +98-21-82884506, Fax: +98-21-82884555,E-mail: aminsh_f@modares.ac.ir 


\section{INTRODUCTION}

The World Health Organization has defined health literacy as "social and cognitive skills that determine the motivation and the ability of individuals to acquire, understand and use health information to improve and maintain good health) by making healthy decisions throughout the life."1)

The concept of health literacy in educational research focuses on developing the skills and capacities that enable people to gain greater control over their health and the factors that shape their health. ${ }^{2)}$ Sorensen et al. ${ }^{3)}$ proposed a coherent definition based on a systematic review on behalf of the Health Literacy Project of Europe. They reported that health literacy refers to the knowledge, motivation, and adequacy of access, ability to understand, evaluate, and use relevant health information in health care, prevention and treatment of disease, and promotion of health throughout life to maintain or improve quality of life. ${ }^{3)}$

Studies have shown the effects of health literacy on the general state of health and its related factors and health outcomes, ${ }^{4)}$ physical and mental health, as well as health-related quality of life. ${ }^{5)}$ People's subjective assessments of their health-related quality of life, feeling of well-being, and ability to function physically, psychologically, and socially are increasingly used as comprehensive indicators of medical interventions and health research. . $^{\text {) }}$

Low health literacy has been associated with poor quality of life owing to reduced accessibility and use of less medical care, increased stress from increasing challenges in everyday life, poor self-management of diseases, and reduced self-efficacy, or the "ability to exert control over life and environment." ${ }^{\prime \prime)}$ Unlike demographic characteristics and social structures that are established and cannot be changed without extensive social and political changes, health literacy is modifiable and can be reinforced by health training. ${ }^{7)}$ Health interventions with the aims of influencing decision-making in the lifestyle and awareness of health determinants and of encouraging individual and collective action may lead to the modification of these factors, resulting in individual and social empowerment and health literacy to achieve health goals. ${ }^{8)}$

University students are faced with a heavy workload and little control over their situations, which can induce a variety of health problems for them. Students are often considered as a select group of people who have little knowledge of their health status and quality of life. ${ }^{9)}$ Although students are often assumed to have adequate health literacy, previous study findings suggest that some students may have difficulty in acquiring, understanding, and acting on health information. Meanwhile, decision-making on health in this stage of life can affect future health behaviors and outcomes. ${ }^{10)}$ As such, students need health literacy skills to improve and maintain good health, prevent diseases, and understand, interpret, and analyze health information. ${ }^{11)}$

Today, the role of electronic resources in human health is becoming increasingly important. ${ }^{12)}$ Health information is one of the most studied topics online. Eight out of 10 internet users reported searching sites at least once when online or checking their e-mails to access health information. ${ }^{13)}$ Students are pioneers in using this tool and are at the forefront of the use of social networking services for communicating with others as a part of college life, compared with adults. ${ }^{14)}$ Given the importance of health literacy in the quality of life of students, this study aimed to investigate the effect of training based on health literacy through social networking strategies to promote health-related quality of life among students at Islamic Azad University, Shahr Rey Branch, Iran.

\section{METHODS}

\section{Study Design and Participants}

This study was a randomized controlled trial conducted on 120 students of Islamic Azad University, Shahr Rey Branch, Tehran, Iran, in 2016. The correlation between the health literacy and quality of life of students was assessed through an analytic descriptive pilot study on 300 students. The findings of the pilot study showed a significant relationship between the total, physical, and mental health scores in quality of life of students and their health literacy level $(\mathrm{P}<0.05)$.

Students were included if they were aged between 18 and 25 years and at least in the second year of their college study. Exclusion criteria were an above-average quality of life score and lack of interest to participate in the study.

\section{Sample Size and Sampling Process}

The sample size of the second stage of the study (intervention phase) was estimated by using the Kappa formula, considering a confidence level of $95 \%$ and study power of $80 \%$. The pilot showed that the mean score of students' health literacy was 0.7 ; therefore, the calculated sample size was 60 participants for each group (considering a $10 \%$ dropout rate). Cluster random sampling was used to select the participants. In this method, three faculties were chosen from all faculties at the Islamic Azad University, Shahr Rey Branch, using a table of random numbers. Five classrooms were selected systematically from each selected faculty. Sampling was performed in two stages: first, the samples were selected with convenience sampling from these classes for the descriptive phase; second, students whose quality of life scores were less than the mean score and who agreed to participate in the study were selected for the interventional phase. The participants were then categorized into subgroups based on the main study factors, including marital status and health condition. Finally, an equal number of participants was randomly assigned into the experimental and control groups, with similar distribution of marital status and health condition.

\section{Research Instruments}

In this study, data collection (pre-test and post-test) was conducted through self-report questionnaires. The questionnaire had three parts: the demographic questionnaire, Test of Functional Health Literacy in Adults (TOFHLA), and Short Form-12 questionnaire of life quality (SF- 
12). The demographic questionnaire included questions on age, sex, marital status, educational level, employment status, job satisfaction, family income, and health status. TOFHLA was used to determine the health literacy of the participants. Javadzade et al. ${ }^{4)}$ assessed its psychometric properties in Iran. The reliability of the numeracy and reading comprehension parts was reported as 0.79 and 0.88 , respectively. The health literacy score of each participant could be in the range of 0-100: 1-59, inadequate; $60-74$, borderline; and 75-100, adequate. SF12 , which was designed in 1996 by Ware et al. ${ }^{15)}$ was used to define the participants' health-related quality of life. Montazeri et al. ${ }^{16)}$ assessed its psychometric properties in Iran in 2009. The reliability of the physical and mental components was reported as 0.73 and 0.72 , respectively. A score of 12-24 was considered 'poor life quality,' 25-36, 'average life quality,' and 37-48, 'good life quality.'16)

\section{Educational Intervention}

The research objectives were explained to the target group, who were subsequently assured of the confidentiality of information. Written consent was obtained from all of the participants. Then, the questionnaires were distributed and completed by the students. Educational programs were provided to the case group, whereas the control group received no intervention. The design and implementation of the educational intervention was performed with regard to health literacy strategies (HLS). ${ }^{17)}$ To this end, an educational session was held using HLS to improve verbal communication (such as teach-back technique).

\section{Educational Instrument}

According to the target population poll on the preferred educational tools and surveys on university students, online messaging services such as Telegram, WhatsApp, and Line were considered as the most suitable methods to transfer message in terms of access to information, cost, ease of training, and scope of context or situation. Another finding was the unwillingness of students to turn to traditional teaching methods (lectures) owing to their being time consuming and interference with class hours.

\section{Educational Contents}

In this research, the contents of the educational intervention were designed based on a health literacy needs assessment conducted using three sources of information: experts' opinion, target group's ideas, and literature review. The opinions of experts (health educator professionals and professor) and the target group were collected through interviews and focus group discussions, respectively. Through literature review, we explored, delineated, and analyzed the current national and international literature with respect to the various aspects of the problem. In this phase of study, the educational needs were determined in two major domains: physiological and psychological. Physical health education consisted of the perception of health, physical performance, physical health, and physical pain. The psychological domain included emotional issues, social performance, vitality, and mental health. These domains were chosen through need assessment phase which is expresed in this section.

Generally, the specific lesson plans were designed to contain six sessions. The first session, lasting about 2 hours, was held in one of the university classes by the health educator (first author) using the three educational methods of lecture, brainstorming, and buzz groups. Buzz groups are a method for quickly and efficiently gathering feedback on a topic or responding to a specific question during a plenary (a session that includes all participants of an event). The succeeding five sessions were held via social networking services. Educational messages were designed based on the 'Simply Put' manual ${ }^{17)}$ and design manual of health literacy-based print media. ${ }^{18)}$ Accordingly, the readability level of the messages and intended educational materials were set using Simple Measure of Gobbledygook (SMOG). ${ }^{17)}$ This formula is the fastest strategy to test the readability level of educational contents. Based on the SMOG guideline, we randomly counted the number of words with three or more syllables in 10 sentences in different parts of the text. Then, the square root of the number was calculated, and 3 was added to the calculated number. Finally, based on the provided table, the level and degree of approximation and predicted grade level were identified. In this study, post-test was performed in two steps: immediately and 3 months after the intervention.

Table 1. Relative frequency distribution of the participants according to demographic characteristics

\begin{tabular}{|c|c|c|c|}
\hline Variable & Experimental group & Control group & P-value* \\
\hline Sex & & & 0.926 \\
\hline Male & $30(51.72)$ & $29(49.15)$ & \\
\hline Female & $28(48.28)$ & $30(50.58)$ & \\
\hline Total & $58(100.0)$ & $59(100.0)$ & \\
\hline Marital status & & & 0.637 \\
\hline Single & $53(91.38)$ & 53 (89.83) & \\
\hline Married & $5(8.62)$ & $6(10.17)$ & \\
\hline Total & $58(100.0)$ & $59(100.0)$ & \\
\hline Education level & & & 0.378 \\
\hline Associate & $38(65.52)$ & $40(67.80)$ & \\
\hline Bachelor & $20(34.48)$ & $19(32.20)$ & \\
\hline Total & $58(100.0)$ & $59(100.0)$ & \\
\hline Age (y) & & & 0.822 \\
\hline $18-21$ & $40(68.97)$ & $41(69.49)$ & \\
\hline $21-25$ & $18(31.03)$ & $18(30.51)$ & \\
\hline Total & $58(100.0)$ & $59(100.0)$ & \\
\hline Income (monthly, USD) & & & 0.383 \\
\hline $125-250$ & 8 (13.79) & $7(11.86)$ & \\
\hline $250-500$ & $35(60.34)$ & $40(67.80)$ & \\
\hline$>500$ & $15(25.86)$ & $12(20.34)$ & \\
\hline Total & $58(100.0)$ & $59(100.0)$ & \\
\hline School & & & 0.723 \\
\hline Art and architecture & $20(34.48)$ & $22(37.29)$ & \\
\hline Management and accounting & $22(37.93)$ & $23(38.28)$ & \\
\hline Humanities & $17(29.31)$ & $13(22.03)$ & \\
\hline Total & $58(100.0)$ & $59(100.0)$ & \\
\hline
\end{tabular}

Values are presented as number (\%).

*Between-group comparison (experimental and control groups) using chi-square test. 


\section{Statistical Analysis}

The data were analyzed using SPSS ver. 16.0 (SPSS Inc., Chicago, IL, USA). Data were assessed for normality using the KolmogorovSmirnov test. Continuous data between groups were presented as means and standard deviations using independent t-test, whereas categorical data were presented as frequency and percentage values using the chi-square test. For the comparison of parametric continuous data, repeated measures analysis of variance with Tukey's test as post hoc test was used. The significance level was set at 0.05 .

\section{Ethical Statement}

This study was approved by the Ethics Committee of the Research Deputy at Tarbiat Modares University (IRB approval no., 6585). Also each participant signed the written informed consent letter before the interview.

\section{RESULTS}

A total of 118 students participated in this study. Their mean age was $21.8 \pm 2.05$ years. Statistical tests showed that the participants in the two groups were similar and homogenous in terms of age, sex, marital status, education level, monthly household income, and field of study (Table 1).

Table 2 shows the comparison results of the two groups in terms of health literacy level. No significant differences were observed before the intervention, but significant differences were observed immediately after and 3 months after intervention $(\mathrm{P}<0.001)$. The mean health literacy score increased significantly 3 months after intervention in the experimental group from $66.62 \pm 16.46$ to $85.7 \pm 9.53(\mathrm{P}<0.001)$, but not in the case of immediately after intervention $(\mathrm{P}=0.888)$. Meanwhile, no significant differences were noted immediately and 3 months after in- tervention in the control group ( $\mathrm{P}=0.644$ and 0.876 , respectively).

There was no significant difference in the scores of quality of life between the two groups $(\mathrm{P}>0.05)$ before intervention; significant differences were only noted immediately and 3 months after intervention $(\mathrm{P}<0.05)$. The mean quality of life scores in the experimental group were significantly different immediately and 3 months after the intervention compared with at the baseline (Table 3).

\section{DISCUSSION}

The study aimed to assess the effect of health literacy education conducted via social networking sites on the promotion of quality of life of university students. The results showed that teaching based on HLS through social networks, increased the quality of life and health literacy of students. The findings of this study are in line with those in existing studies. Tol et al. ${ }^{19)}$ assessed the effect of training on the awareness and health literacy of patients and found a significant improvement in health literacy in the experimental group.

Our study also showed that the use of HLS, including teach-back techniques, print media manuals, and adjustment of the reading level of educational materials according to grade level, can be effective in the learning process. Reisi et al. ${ }^{20)}$ applied these strategies to increase self-care among patients with diabetes and identified a significant improvement in patients' health literacy. In another study, interactivevoice response calls were used along with personal logs and self-monitoring action plans to reduce the consumption of sugar-sweetened beverages in rural citizens of Virginia, in the United States. ${ }^{21)}$ A systematic review on 36 published articles reported that the effect of health education using the internet depends on the approach and aim of the study; web-based education has been most successful in studies that utilized cognitive behavior therapy and in studies with the aim of im-

Table 2. Comparison of mean scores in health literacy of the two groups: before, immediately after, and 3 months after intervention

\begin{tabular}{|c|c|c|c|c|c|}
\hline \multirow{2}{*}{ Health literacy } & \multicolumn{2}{|c|}{ Experimental group } & \multicolumn{2}{|c|}{ Control group } & \multirow{2}{*}{ P-value } \\
\hline & Mean $\pm S D$ & P-value* & Mean \pm SD & P-value* & \\
\hline Before intervention & $66.62 \pm 16.46$ & & $66.71 \pm 20.12$ & & 0.979 \\
\hline Immediately after intervention & $81.81 \pm 9.54$ & 0.888 & $70.90 \pm 19.10$ & 0.644 & 0.000 \\
\hline 3 Months after intervention & $85.7 \pm 9.53$ & 0.000 & $71.72 \pm 17.96$ & 0.867 & 0.000 \\
\hline Immediately and 3 months after & & 0.374 & & 0.551 & \\
\hline
\end{tabular}

SD, standard deviation.

*Within-group comparison using Tukey's test. 'Between-group comparison (experimental and control groups) using independent t-test.

Table 3. Comparison of the mean scores in life quality of the two groups: before, immediately after, and 3 months after intervention

\begin{tabular}{|c|c|c|c|c|c|}
\hline \multirow{2}{*}{ Quality of life } & \multicolumn{2}{|c|}{ Experimental group } & \multicolumn{2}{|c|}{ Control group } & \multirow{2}{*}{ P-value } \\
\hline & Mean $\pm S D$ & P-value* & Mean $\pm S D$ & P-value* & \\
\hline Before intervention & $31.79 \pm 3.77$ & & $30.94 \pm 4.40$ & & 0.269 \\
\hline Immediately after intervention & $36.21 \pm 2.65$ & 0.000 & $31.62 \pm 3.19$ & 0.569 & 0.000 \\
\hline 3 Months after intervention & $38.76 \pm 2.52$ & 0.000 & $31.39 \pm 3.22$ & 0.531 & 0.000 \\
\hline Immediately and 3 months after intervention & & 0.000 & & 0.645 & \\
\hline
\end{tabular}

SD, standard deviation.

*Within group comparison using Tukey's test. 'Between-group comparison (experimental and control groups) using independent t-test. 
proving depressive symptoms. ${ }^{22)}$ Schillinger et al. ${ }^{23)}$ identified a significant effect with the use of teach-back techniques. Other studies have revealed a significant improvement with the use of visual media. ${ }^{24,25)}$ The usefulness of print media and adjustment of the reading level according to grade level has also been documented. ${ }^{26)}$

The present study showed that training based on health literacy can improve students' quality of life. This finding is consistent with those in previous studies, which attributed significant improvements in the quality of life of university students to health education. ${ }^{27,28)}$ The findings of the current research indicated that HLS can help people obtain and understand health information easier. Health literacy education also enabled the present participants to make informed decisions. Meanwhile, low health literacy can be a gap between the educator and the learners. As such, it is essential to evaluate the health literacy of the target population with an available health literacy measurement tool. Designing the curriculum according to the level of health literacy skills is suggested.

In this study, texting to students took place through social networking services. In Iran, only one study has assessed the effect of the use of social networking services in training students. ${ }^{29)}$ The findings of Jafari et al. ${ }^{30)}$ showed the positive effect of electronically nutrition training on lowering blood sugar. Based on the findings of these studies, we hypothesized that health education can be effective via Telegram, as most students take advantage of this platform during day time, thereby ensuring that educational materials could be made readily available to them. Further, feedback could be obtained promptly from the participants, which plays an important role in the training process and future materials to be sent. Additionally, students tended to be less inclined toward traditional teaching methods (lectures), according to their statements. In the preparation of the text messages, everyday words that are easily understood should be utilized, along with appropriate white space and simple images that help clarify the message. The reading level of messages should be adjusted to match that of the intended recipients using the SMOG formula.

\section{Conclusions}

The present study showed the significant effect of delivering educational interventions via social networking services, which can be applied in health educational programs. The effectiveness of internetbased education in young people can serve as a basis for developing health literacy-enhancing interventions and capturing the different dimensions of health literacy within the health care, disease prevention, and health promotion settings.

\section{Study Limitations}

The self-report method of completing questionnaires could cause over- or under-estimation of the results and thereby limit the results of the study. The instructors who agreed to participate in the study were few and not representative. Moreover, psychological differences were not controllable in this study. Thus, it is recommended that further studies take into account measures to assess the effect of psychological factors on the learning process in health education through social networking services.

\section{CONFLICT OF INTEREST}

No potential conflict of interest relevant to this article was reported.

\section{ACKNOWLEDGMENTS}

We would like to appreciate the authorities of Tarbiat Modares University of Medical Sciences for the scientific and ethical approval and financial support of this research. We also thank the cooperation of authorities of Islamic Azad University, Shahr Rey and students who participated in this study.

\section{ORCID}

Mahnaz Khaleghi: https://orcid.org/0000-0002-5883-8012

Farkhonde Amin Shokravi: https://orcid.org/0000-0001-7013-0167

Nooshin Peyman: https://orcid.org/0000-0002-6218-4787

Maryam Moridi: https://orcid.org/0000-0002-5999-982X

\section{REFERENCES}

1. World Health Organization Regional Office for South-East Asia. Health literacy toolkit for low- and middle-income countries: a series of information sheets to empower communities and strengthen health systems [Internet]. Geneva: World Health Organization; 2015 [cited 2018 Jan 17]. Available from: http://www.who.int/iris/handle/10665/205244.

2. Nutbeam D. Health literacy as a public health goal: a challenge for contemporary health education and communication strategies into the 21st century. Health Promot Int 2000;15:259-67.

3. Sorensen K, van den Broucke S, Fullam J, Doyle G, Pelikan J, Slonska Z, et al. Health literacy and public health: a systematic review and integration of definitions and models. BMC Public Health 2012;12:80.

4. Javadzade SH, Sharifirad G, Radjati F, Mostafavi F, Reisi M, Hasanzade A. Relationship between health literacy, health status, and healthy behaviors among older adults in Isfahan, Iran. J Educ Health Promot 2012;1:31.

5. Howard DH, Sentell T, Gazmararian JA. Impact of health literacy on socioeconomic and racial differences in health in an elderly population. J Gen Intern Med 2006;21:857-61.

6. Wang C, Kane RL, Xu D, Meng Q. Health literacy as a moderator of health-related quality of life responses to chronic disease among Chinese rural women. BMC Womens Health 2015;15:34.

7. Nutbeam D. The evolving concept of health literacy. Soc Sci Med 2008;67:2072-8.

8. Kanj M, Mitic W. Promoting health and development: closing the implementation gap. Proceedings of the 7th Global Conference on Health Promotion; 2009 Oct 26-30; Nairobi, Kenya. Geneva: World Health Organization; 2009.

9. Vaez M, Laflamme L. Health behaviors, self-rated health, and quality of life: a study among first-year Swedish university students. J Am Coll 
Health 2003;51:156-62.

10. Ickes MJ, Cottrell R. Health literacy in college students. J Am Coll Health 2010;58:491-8.

11. National Center for Chronic Disease Prevention and Health Promotion. Measuring physical activity intensity [Internet]. Atlanta (GA): Centers for Disease Control and Prevention; 2011 [cited 2018 Apr 15]. Available from: http://www.cdc.gov/physicalactivity.

12. Pagliari C, Sloan D, Gregor P, Sullivan F, Detmer D, Kahan JP, et al. What is eHealth (4): a scoping exercise to map the field. J Med Internet Res 2005; 7:e9.

13. Stellefson M, Hanik B, Chaney B, Chaney D, Tennant B, Chavarria EA. eHealth literacy among college students: a systematic review with implications for eHealth education. J Med Internet Res 2011;13:e102.

14. Jones S, Johnson-Yale C, Millermaier S, Perez FS. Everyday life, online: U.S. college students' use of the Internet. First Monday [Internet]. 2009 [cited 2018 Apr 15]. Available from: http://firstmonday.org/ojs/index. $\mathrm{php} / \mathrm{fm} /$ article/view/2649/2301.

15. Ware J Jr, Kosinski M, Keller SD. A 12-item Short-Form Health Survey: construction of scales and preliminary tests of reliability and validity. Med Care 1996;34:220-33.

16. Montazeri A, Vahdaninia M, Mousavi SJ, Omidvari S. The Iranian version of 12-item Short Form Health Survey (SF-12): factor structure, internal consistency and construct validity. BMC Public Health 2009;9:341.

17. Centers for Disease Control and Prevention. Simply Put: a guide for creating easy-to-understand materials [Internet]. Atlanta (GA): Strategic and Proactive Communication Branch, Centers for Disease Control and Prevention; 2009 [cited 2018 Jan 3]. Available from: https:// www.cdc.gov/healthliteracy/pdf/Simply_Put.pdf.

18. DeWalt DA, Broucksou KA, Hawk V, Brach C, Hink A, Rudd R, et al. Developing and testing the health literacy universal precautions toolkit. Nurs Outlook 2011;59:85-94.

19. Tol A, Pourreza A, Rahimi Foroshani A, Tavassoli E. Assessing the effect of educational program based on small group on promoting knowledge and health literacy among women with type2 diabetes referring to selected hospitals affiliated to Tehran University of Medical Sciences. Razi J Med Sci 2013;19:1-10.

20. Reisi M, Mostafavi F, Javadzade H, Mahaki B, Tavassoli E, Sharifirad G. Impact of health literacy, self-efficacy, and outcome expectations on adherence to self-care behaviors in Iranians with type 2 diabetes. Oman Med J 2016;31:52-9.

21. Bailey AN, Porter KJ, Hill JL, Chen Y, Estabrooks PA, Zoellner JM. The impact of health literacy on rural adults' satisfaction with a multicomponent intervention to reduce sugar-sweetened beverage intake. Health Educ Res 2016;31:492-508.

22. Paul CL, Carey ML, Sanson-Fisher RW, Houlcroft LE, Turon HE. The impact of web-based approaches on psychosocial health in chronic physical and mental health conditions. Health Educ Res 2013;28:45071.

23. Schillinger D, Piette J, Grumbach K, Wang F, Wilson C, Daher C, et al. Closing the loop: physician communication with diabetic patients who have low health literacy. Arch Intern Med 2003;163:83-90.

24. Davidson R, Duerson M, Rathe R, Pauly R, Watson RT. Using standardized patients as teachers: a concurrent controlled trial. Acad Med 2001;76:840-3.

25. Nasim A, Blank MD, Cobb CO, Berry BM, Kennedy MG, Eissenberg T. How to freak a Black \& Mild: a multi-study analysis of YouTube videos illustrating cigar product modification. Health Educ Res 2014;29:4157.

26. Wallace LS, Roskos SE, Weiss BD. Readability characteristics of consumer medication information for asthma inhalation devices. J Asthma 2006;43:375-8.

27. Soltani Shal R, Aghamohammadian Sharbaf H, Ghanaei Chamanabad A. Effect of exercise on general health, quality of sleep and quality of life in Ferdowsi University of Mashhad students. J Qazvin Univ Med Sci 2013;17:39-46.

28. Mahmoodi M, Zahrakar K, Shabani H. The effectiveness of life skills training on the improvement of students' life quality. J Iran Psychol 2013;10:71-9.

29. Cheragh Mohaei L, Sarami G, Kadivar P, Montazar G. Design of virtual social networks based education and its impact on students learn to make realistic [dissertation]. Tehran: Teacher Training University; 2013.

30. Jafari M, Pasdar Y, Rezaei M, Mahdizadeh H, Ashtarian H. The effect of nutrition education using blogs, group-collaborative blogs and short messaging on lipids profiles and glucose in patients with type II diabetes. Med J Mashhad Univ Med Sci 2013;56:261-6. 